\title{
Cultivation of microalgae Chlorella using wine industry by-products
}

\author{
Lidia Martin-Gordillo, María Cuaresma ${ }^{1}$, Ma Ángeles Fernández-Recamales², Ana Sayago², \\ Carlos Vílchez ${ }^{1}$ and Inés Garbayo ${ }^{1, *}$ \\ 1 Algal Biotechnology Group, Ciderta and RENSMA (Center of Research in Natural Resources, Health and \\ Environment), University of Huelva, 21007 Huelva, Spain; lidiadelasmercedes.martin226@alu.uhu.es \\ (L.M.); maria.cuaresma@dqcm.uhu.es (M.C.); cvilchez@uhu.es (C.V.); garbayo@uhu.es (I.G). \\ 2 Dpt. of Chemistry, Faculty of Experimental Science. University of Huelva, 21007 Huelva, Spain; \\ recamale@uhu.es (A.F.R.); ana.sayago@dqcm.uhu.es (A.S.). \\ * Correspondence: garbayo@uhu.es; Tel.: +34-959219953; Fax: +34-959219942 \\ † Presented at the $1^{\text {st }}$ International Electronic Conference on Microbiology in 2020 (ECM 2020), \\ 02-30 November 2020; Available online: https://ecm2020.sciforum.net/
}

Published: 30 November 2020

\begin{abstract}
An approach of new and sustainable uses for by-products generated in the wine production industry, one of the agro-food sectors of importance, has been studied. Wine lees, a sediment obtained in different processes of decantation of wine, have been used to produce biomass of microalgae enriched in carotenoids as high added value biomolecules. Experiments to incorporate chemical components of wine lees into microalgae biomass to understand the effect of these residues on the growth and biosynthesis of carotenoids into commercial microalgae Chlorella sorokiniana have been done. Algal culture system has been optimized and preparation of culture media have been obtained by extracting in water the soluble nutrients contained in the lees at different concentrations between $5 \%$ and $50 \% \mathrm{w} / \mathrm{v}$. Optimal growth was obtained using extraction of wine residues at $5 \%$ and $10 \% \mathrm{w} / \mathrm{v}$. At $10 \%$ oxidative stress, measured as carotenoids production (specially lutein) and antioxidant activity (DPPH method), was more intense than the obtained using residues at $5 \%$. Our results show that growth in culture media prepared with wine lees extracts stimulated the antioxidant activity and the production of carotenoids in C. sorokiniana cells. Preliminary information, not only to produce sustainable growth media for biomass of microalgae enriched in high value molecules, but also to reuse nutrients contained in wine industry by-products what is of particular interest in the context of a circular economy is provided.
\end{abstract}

Keywords: C. sorokiniana; wine industry by-products; microalgae biomass; carotenoids

\section{Introduction}

Valorization of agroindustrial by-products in biotechnology research is one of the most important challenges of circular economy. In the case of wine production industry, it has become important to find new uses for the large amounts of residues generated each year which represents an environmental issue [1]. As by-products, wine lees are considered a source of bioactive compounds with antioxidant activity due to phenolic compounds and could be valorized and recycled to avoid environmental pollution [2].

Microalgae are able to assimilate organic compounds for biomass production and previous studies have described supplementation of algae culture media with agricultural waste such as dairy manure, wastewater from fruit, vegetable or cultivated plant processing [3]. However, the incorporation of wine lees, a sediment obtained in different processes of decantation of wine, has been scarcely explored to obtain microalgae biomass. The aim of the present study was focused 
on the development of new strategies to use agro-food industry by-products from wine production, in order to produce biomass of microalgae C. sorokiniana enriched in bioactive molecules, as carotenoids.

\section{Materials and Methods}

\subsection{Microorganism and culture conditions}

Microalgae $C$. sorokiniana was obtained from the UTEX culture collection. It was maintained in modified M-8 medium [4] that was prepared as follows: $\mathrm{KH}_{2} \mathrm{PO}_{4}, 0.74 \mathrm{gL}^{-1} ; \mathrm{Na}_{2} \mathrm{HPO}_{4} \times 2 \mathrm{H}_{2} \mathrm{O}, 0.26$ $\mathrm{gL}^{-1} ; \mathrm{MgSO}_{4} \times 7 \mathrm{H}_{2} \mathrm{O}, 0.4 \mathrm{gL}^{-1} ; \mathrm{CaCl}_{2} \times 2 \mathrm{H}_{2} \mathrm{O}, 0.013 \mathrm{gL}^{-1} ; \mathrm{KNO}_{3}, 3 \mathrm{gL}^{-1}$; EDTA ferric sodium salt, 0.116 $\mathrm{gL}^{-1}$; $\mathrm{Na}_{2} \mathrm{EDTA} \times 2 \mathrm{H}_{2} \mathrm{O}, 0.0372 \mathrm{gL}^{-1} ; \mathrm{H}_{3} \mathrm{BO}_{3}, 6.18 \times 10^{-5} \mathrm{gL}^{-1} ; \mathrm{MnCl}_{2} \times 4 \mathrm{H}_{2} \mathrm{O}, 1.3 \times 10^{-2} \mathrm{gL}^{-1} ; \mathrm{ZnSO}_{4} \times$ $7 \mathrm{H}_{2} \mathrm{O}, 3.20 \times 10^{-3} \mathrm{gL}^{-1} ; \mathrm{CuSO}_{4} \times 5 \mathrm{H}_{2} \mathrm{O}, 3.2 \times 10^{-3} \mathrm{gL}^{-1}$. The $\mathrm{pH}$ was adjusted to 6.7-6.8. Cultures were grown at $25{ }^{\circ} \mathrm{C}$, bubbled with air containing $2.5 \%(\mathrm{v} / \mathrm{v}) \mathrm{CO}_{2}$, as unique carbon source, and continuously illuminated with fluorescent lamps with $100 \mu \mathrm{mol}$ of photons $/ \mathrm{m}^{2} / \mathrm{s}$ of white light at the surface of the flask. The irradiance was measured with a photoradiometer Delta OHM (mod. HD9021).

\subsection{Analytical determinations}

Pigments were measured spectrophotometrically using aliquots $(1 \mathrm{ml})$ of the cultures which cells were spinned down after $5 \mathrm{~min}$ at $4400 \mathrm{rpm}$ at $4^{\circ} \mathrm{C}$. To the obtained pellet $4 \mathrm{ml}$ of pure methanol were added and the resulted suspension incubated first at $60^{\circ} \mathrm{C}$ during $30 \mathrm{~min}$ and after at $0^{\circ} \mathrm{C}$ during $10 \mathrm{~min}$ and centrifuged during $5 \mathrm{~min}$ at $4400 \mathrm{rpm}$. Chlorophyll and total carotenoid concentration were determined in the supernatant, using the equations proposed by Wellburn [5].

\subsection{Pigment and antioxidant activity analysis}

Pigments were extracted with methanol and measured spectrophotometrically as described in [6]. Specific carotenoids-lutein and $\beta$-carotene-were separated by HPLC equipped with a diode-array detector (L-7420, TermoQuest, CA, USA) and a RP18 column (LichroCart RP18, Merck), $5 \mu \mathrm{m}$, size $250 \times 4 \mathrm{~mm}$. In the mobile phase, solvent $A$ was ethyl acetate and solvent $B$ was acetonitrile and water $(9: 1, \mathrm{v} / \mathrm{v})$ (mobile phase flow rate was $1 \mathrm{~mL}$ per minute). Carotenoids detection was at 450 $\mathrm{nm}$ and the carotenoids were quantified using lutein and $\beta$-carotene standards supplied by DHI-Water and Environment (Hørsholm). Antioxidant activity measured as DPPH was determined as described by [7].

\subsection{Dry weight measurements}

To measure the dry weight, $5 \mathrm{ml}$ of each culture were taken and the liquid medium was removed by means of a vacuum pump using a cellulose acetate filter (weighed before using it) with $0.45 \mu \mathrm{m}$ pore size from Sartorius (Goettingen) to separate the cells from the medium. The cells were then washed with demineralized water before drying the filters. The filters with the cells were dried and stoved at $100{ }^{\circ} \mathrm{C}$. The filters with the dried cells were weighed after $24 \mathrm{~h}$.

\subsection{Maximum Photosystem II Quantum Yield}

The photosynthetic efficiency was evaluated by measuring the chlorophyll fluorescence in dark-acclimated cells, considered as the maximum photosynthetic efficiency of photosystem II. This parameter was determined using a portable pulse amplitude modulated fluorometer (AquaPen-C AP-C 110, Photo Systems Instruments), according to the method described by [8].

\section{Results and Discussion}

Cultivation procedure of the microalgae C. sorokiniana using by-products from the wine industry. 
First step to obtain stable growth of the microalgae C. sorokiniana was to optimize culture media prepared with soluble nutrients (MSN) extracted from lees as wine residues. For this, lees were extracted with distilled water at room temperature, using them at different concentrations between $5 \%$ and $50 \% \mathrm{w} / \mathrm{v}$.

Cell cultures of the microalgae were incubated with media obtained by extraction of wine residues at $0 \%$ (control culture), 5\%, 10\%, 20\%, 30\%, 40\% and 50\% w/v. The cultures were grown at $25{ }^{\circ} \mathrm{C}$, bubbled with air containing $5 \%(\mathrm{v} / \mathrm{v}) \mathrm{CO}_{2}$ and continuously illuminated with fluorescent lamps. Throughout 4 days ( $96 \mathrm{~h}$ ) of experiment, samples of the different cultures were taken to determine the evolution of specific growth parameters as chlorophyll, total carotenoid content and quantum yield (QY) as an indicator of cell viability and status of the photosystem II. Results are shown in Figure 1 (A, B and C). As it can be seen in Figure 1A, highest values in chlorophyll concentration were obtained after $48 \mathrm{~h}$ with MSN cultures prepared with 5,10 and 20\% w/v of lees. Maximum values of QY were determined with 5 and 10\% MSN indicating an optimal growth of cells in both concentrations. A loss of cell viability was observed in cultures of $40 \%$ and $50 \% \mathrm{w} / \mathrm{v}$ indicating a toxic effect of wine by-products in C. sorokiniana cells. Total carotenoid profile (Figure 1C) shows a higher production, and a stronger antioxidant response, with both 5 and $10 \%$ MSN cultures.

(A)

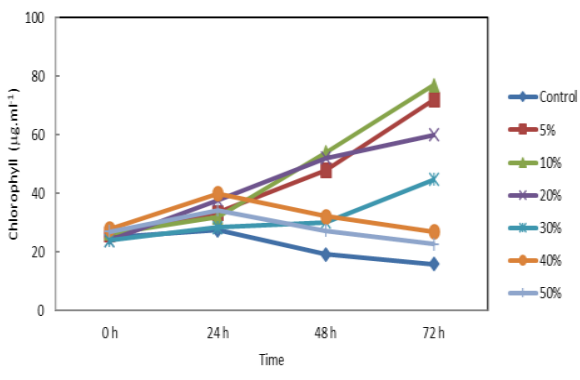

(B)

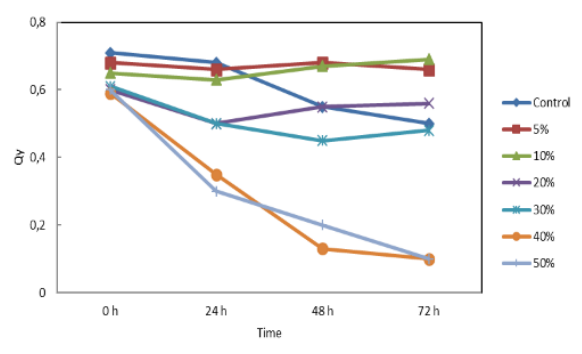

(C)

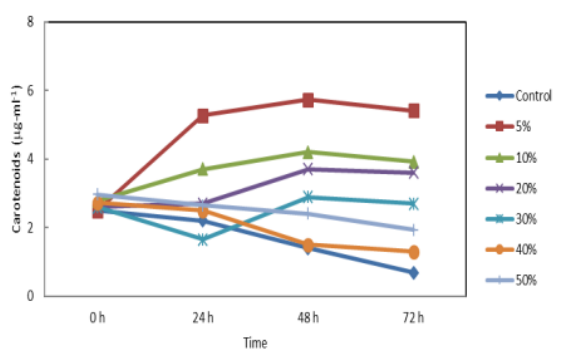

Figure 1. Evolution of chlorophyll, quantum yield and total carotenoid content in C. sorokiniana cultures prepared with MSN at different concentrations. Cell cultures of the microalgae were incubated with media obtained by extraction of wine residues (MSN) at 5\%, 10\%, 20\%, 30\%, 40\% and $50 \% \mathrm{w} / \mathrm{v}$. Both cultures were inoculated with $25 \mu \mathrm{g} \mathrm{Chl} / \mathrm{ml}$, with $100 \mu \mathrm{mol}$ of photons $/ \mathrm{m}^{2} / \mathrm{s}$ of white light, incubated at a temperature of $25{ }^{\circ} \mathrm{C}$ and were fluidized with air enriched in $\mathrm{CO}_{2}(5 \% \mathrm{v} / \mathrm{v})$. Chlorophyll content $\left(\mu \mathrm{g} \mathrm{ml}^{-1}\right)(\mathrm{A})$; quantum yield (QY) (B) and total carotenoid content $\left(\mu \mathrm{g} \mathrm{ml} \mathrm{l}^{-1}\right)(\mathrm{C})$ were calculated throughout the experiment as indicated in Materials and Methods section.

To evaluate the antioxidant response of cultures due to residues from the wine industry, specific carotenoids were identified and quantified from cultures under standard conditions. First, a typical chromatogram obtained from methanol extracts of $C$. sorokiniana is shown in Figure 2. HPLC analysis of the accumulated carotenoids showed that lutein plays a significant role in the antioxidant response of the microalgae as it appears as the main carotenoid in terms of quantity. Other carotenoids as $\beta$-carotene, neoxanthin, violaxanthin and zeaxanthin are involved in the antioxidant response by scavenging reactive oxygen species and light excess dissipation [9]. Peak identification was done using commercial standards.

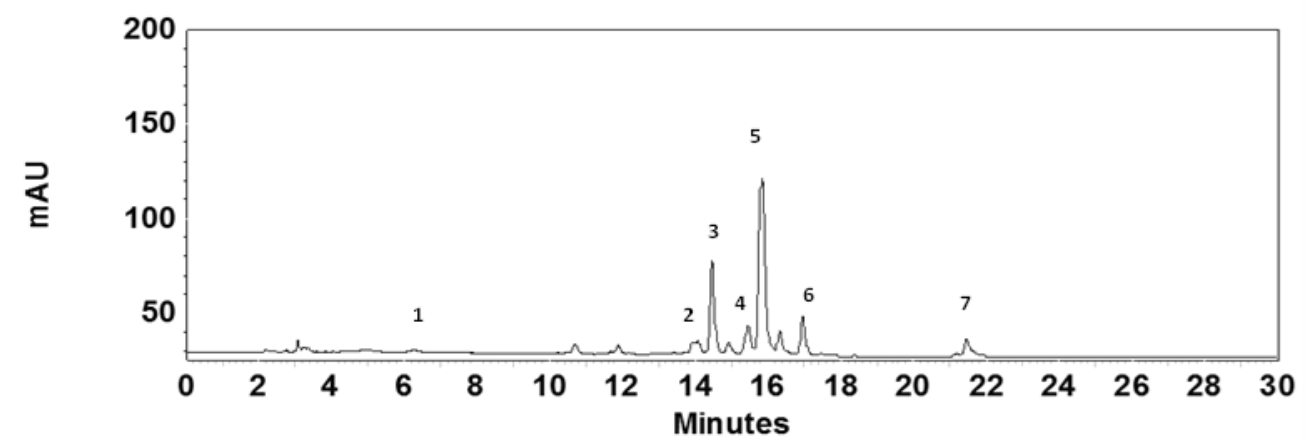


Figure 2. HPLC analysis of carotenoids from C. sorokiniana extracts. Peak assignment is as follows: (1) Neoxanthin, (2) Violaxanthin, (3) Lutein, (4) Zeaxanthin, (5) Chlorophyll b, (6) Chlorophyll a, (7) $\beta$-carotene. The separation and identification procedure is described in Materials and Methods section.

To evaluate if antioxidant response of $C$. sorokiniana cells increased using MSN media, a growth experiment was performed with cultures prepared at 5 and $10 \% \mathrm{w} / \mathrm{v}$ where maximum values of chlorophyll, QY and total carotenoid were determined (Figure 1). Throughout 8 days (192 h) of experiment, samples to determine carotenoids lutein and $\beta$-carotene by HPLC were taken and content $[\mathrm{mg} / \mathrm{g} \mathrm{dw}]$ in cultures prepared with MSN at $5 \%$ and $10 \%$ are shown in Figure 3.

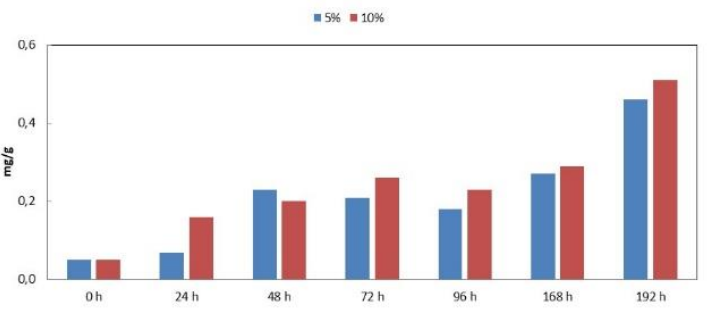

(A)

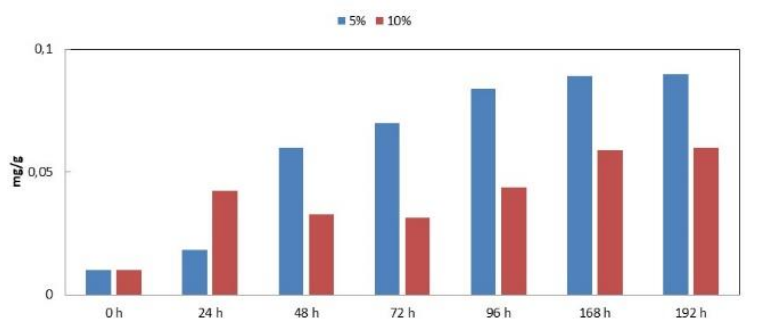

(B)

Figure 3. Carotenoid content of $C$. sorokiniana cultures prepared with MSN at different concentrations. Microalgae cultures were incubated with media obtained by extraction of wine residues (MSN) at 5\% and 10\%. Both cultures were inoculated with $25 \mu \mathrm{g} \mathrm{Chl} / \mathrm{ml}$, with $100 \mu \mathrm{mol}$ of photons $/ \mathrm{m}^{2} / \mathrm{s}$ of white light, incubated at a temperature of $25^{\circ} \mathrm{C}$ and were fluidized with air enriched in $\mathrm{CO}_{2}(5 \% \mathrm{v} / \mathrm{v})$. Content of lutein (A) and $\beta$-carotene (B), expressed in $\mathrm{mg} / \mathrm{g}$, were calculated by HPLC throughout the experiment $(192 \mathrm{~h})$ as indicated in Materials and Methods section.

In media obtained by extraction of wine residues (MSN) at $5 \%$ and $10 \% \mathrm{w} / \mathrm{v}$, the synthesis of all carotenoids of $C$. sorokiniana was stimulated, except for zeaxanthin in which after the first $48 \mathrm{~h}$, there was a decrease in both cultures at 5 and 10\% (data not shown). In the case of lutein, a higher production was observed for cells grown in MSN cultures at $10 \% \mathrm{w} / \mathrm{v}$, although this microalga is not one of the major producers of this carotenoid of commercial interest. For neoxanthin and violaxanthin (data not shown), an increase in their synthesis was also observed at the end of the experiment using MSN cultures of $10 \% \mathrm{w} / \mathrm{v}$. For $\beta$-carotene the highest increase appeared in media prepared at $5 \% \mathrm{w} / \mathrm{v}$.

The antioxidant activity of C. sorokiniana grown in 5\% and 10\% MSN cultures was also determined using, 1,1-diphenyl-2-picrylhydrazyl (DPPH) that measure the ability of antioxidants to scavenge a radical [7]. Results at the end of the experiment (192h) are shown in Figure 4. As it can be seen, highest antioxidant activity was reached using MSN cultures at $10 \% \mathrm{w} / \mathrm{v}$ what it could be the cause of the increase in carotenoid content (specially in lutein) observed in Figure 3A [10].

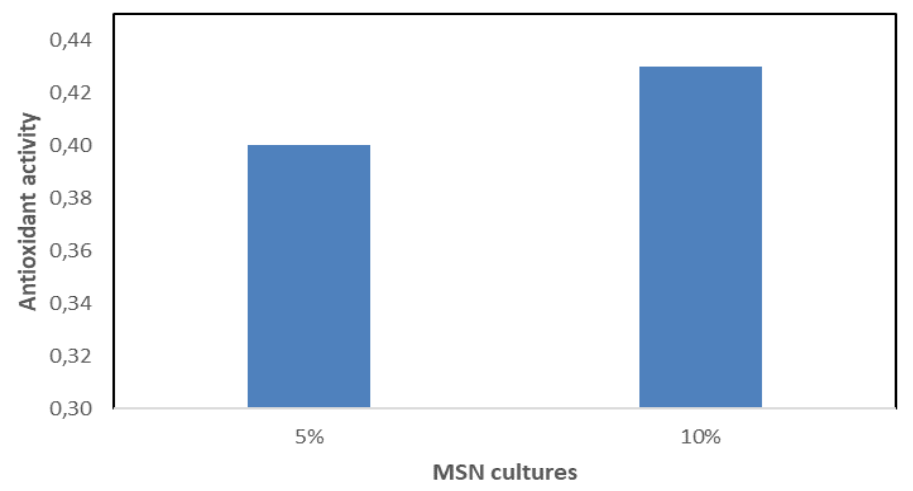

Figure 4. Antioxidant activity (DPPH) of C. sorokiniana cultures prepared with MSN at different concentrations. Microalgae cultures were incubated with media obtained by extraction of wine residues (MSN) at 5\% and 10\% w/v. Both cultures were inoculated with $25 \mu \mathrm{g} \mathrm{Chl} / \mathrm{ml}$, with $100 \mu \mathrm{mol}$ 
of photons $/ \mathrm{m}^{2} / \mathrm{s}$ of white light, incubated at a temperature of $25{ }^{\circ} \mathrm{C}$ and were fluidized with air enriched in $\mathrm{CO}_{2}(5 \% \mathrm{v} / \mathrm{v})$. Antioxidant activity expressed as $\left(\mu \mathrm{mol} \mathrm{DPPH} \mathrm{min}^{-1} \mathrm{ml}^{-1} 10^{2}\right)$, was calculated at the end of the experiment (192h) as indicated in Materials and Methods section.

\section{Conclusions}

1- Culture media to grow microalgae $C$. sorokiniana using by-products from the wine industry has been optimized, extracting with distilled water at room temperature the soluble nutrients contained in wine lees using them at different concentrations $\mathrm{w} / \mathrm{v}$.

2- Stable cultures of the microalgae $C$. sorokiniana have been obtained using culture media prepared with soluble nutrients (MSN) extracted from lees as wine residues at concentrations from $5 \%$ to $30 \% \mathrm{w} / \mathrm{v}$. Optimal growth was reached with MSN cultures prepared at both $5 \%$ and $10 \% \mathrm{w} / \mathrm{v}$.

3- At $10 \%$ oxidative stress, measured as carotenoids production (specially lutein) and antioxidant activity (DPPH method), was more intense than the obtained using residues at $5 \%$. Our results show that growth in culture media prepared with wine lees extracts stimulated the antioxidant activity and the production of carotenoids in C. sorokiniana cells.

4- A first approach in the search for new and sustainable uses of wine industry by-products in the context of a circular economy is presented as these residues could be used to obtain carotenoid-enriched microalgae biomass.

Author Contributions: Conceptualization, I.G., C.V. and L.M.; methodology, L.M., A.S., and A.F.R.; resources, I.G. and C.V.; investigation, L.M., M.C., A.F.R., and I.G.; data curation, I.G., A.S., M.C., and A.F.R..; supervision: I.G.; writing-original draft preparation, I.G., C.V. and M.C.; writing-review and editing, I.G., L.M, M.C., and C.V. All authors have read and agreed to the published version of the manuscript.

Funding: This research was funded by PROGRAMA OPERATIVO FEDER ANDALUCIA 2014-2020. Proyectos de I+D+I., grant number UHU-1265804.

Acknowledgments: Authors are thankful to University of Huelva and PROGRAMA OPERATIVO FEDER ANDALUCIA 2014-2020. Proyectos de I+D+I., grant number UHU-1265804. Authors are also thankful to Denominación de Origen Condado de Huelva (Huelva, Spain) for their support and kind supply of wine by-products used for experiments.

Conflicts of Interest: The authors declare no conflict of interest.

\section{Abbreviations}

MSN: Medium prepared with Soluble Nutrients of wine by-products $\mathrm{w} / \mathrm{v}$ : weight/volume

DPPH: 1,1-diphenyl-2-picrylhydrazyl

\section{References}

1. Devesa-Rey R.; Vecino X.; Varela-Alende J.L.; Barral M.T.; Cruz J.M.; Moldes A.B. Valorization of winery waste vs. the costs of not recycling. Waste Manag 2011, 31 2327-2335.

2. Moreira M.M.; Rodrigues F.; Dorosh O.; Pinto D.; Costa P.C.; Švarc-Gajić J.; Delerue-Matos C. Vine-Canes as a Source of Value-Added Compounds for Cosmetic Formulations. Molecules 2020 25(13): 2969. doi: 10.3390/molecules25132969.

3. Piasecka A.; Nawrocka A.; Wiącek D., Krzemińska I. Agro-industrial by-product in photoheterotrophic and mixotrophic culture of Tetradesmus obliquus: production of $\omega 3$ and $\omega 6$ essential fatty acids with biotechnological importance. Sci Rep 2020 10:6411. https://doi.org/10.1038/s41598-020-63184-4.

4. Mandalam R.K.; Palsson B. Elemental balancing of biomass and medium composition enhances growth capacity in high density Chlorella vulgaris cultures. Biotechnol Bioeng 1998 59: 605-611.

5. Wellburn, A. R. The spectral determination of chlorophyll and b, as well as total carotenoids, using various solvents with spectrophotometers of different resolution. J Plant Physiol 1994 144: 307-313.

6. Ruiz-Domínguez M.C.; Vaquero I.; Obregón V.; De la Morena B.; Vílchez C.; Vega J.M. Lipid accumulation and antioxidant activity in the eukaryotic acidophilic microalga Coccomyxa sp. (strain onubensis) under nutrient starvation. J Appl Phyco l 2014 27:1099-1108. 
7. Brand-Williams, W.; Cuvelier M. E.; Berset C. Use of a free radical method to evaluate antioxidant activity. Food Sci Technol-LEB 1995 38:25-30.

8. Schreiber, U.; Endo, T.; Mi, H.; Asada, K. Quenching analysis of chlorophyll fluorescence by the saturation pulse method: particular aspects relating to the study of eukaryotic algae and cyanobacteria. Plant Cell Physiol 1995 36: 873-882.

9. Forján, E.; Vílchez, C.; Vega, J.M. Biotecnología de microalgas. 2014. H 201-2014.

10. Marxen K.; Vanselow K. H.; Lippemeier S.; Hintze R.; Ruser A.; Hansen U-P. Determination of DPPH radical oxidation caused by methanolic extracts of some microalgal species by linear regression analysis of spectrophotometric measurements. Sensors, 2007 7:2080-2095.

Publisher's Note: MDPI stays neutral with regard to jurisdictional claims in published maps and institutional affiliations.

(C) 2020 by the authors. Submitted for possible open access publication under the terms and conditions of the Creative Commons Attribution (CC BY) license (http://creativecommons.org/licenses/by/4.0/). 